\title{
Crouching theropod and Navahopus sauropodomorph tracks from the Early Jurassic Navajo Sandstone of USA
}

\author{
Jesper Milàn, David B. Loope, and Richard G. Bromley
}

Acta Palaeontologica Polonica 53 (2), 2008: 197-205 doi:http://dx.doi.org/10.4202/app.2008.0203

Numerous tracks and trackways are preserved in the a cross-strata of the Lower Jurassic Navajo Sandstone of northern Arizona and southern Utah, USA. Tracks and trackways of small theropod dinosaurs are particularly abundant within one 10-m-thick interval. This paper describes a crouching trace from a theropod dinosaur that shows impressions of all four limbs, the ischial callosity, the tail, and tracks leading to and away from the crouching site, and revises the interpretation of a well preserved trackway hitherto referred to the synapsid ichnogenus Brasilichnium and here considered to be from a sauropodomorph dinosaur. It is named Navahopus coyoteensis isp. nov. on the basis of morphological differences from the type ichnospecies $N$. falcipollex. The ichnofamily Navahopodidae is revised to include Tetrasauropous unguiferus, Navahopus falcipollex, and N. coyoteensis.

Key words: Navahopus, Navahopodidae, Sauropodomorpha, Theropoda, ichnology, locomotory habits, crouching trace

Jesper Milàn [Milan@geol.ku.dk] and Richard G. Bromley [rullard@geol.ku.dk], Department of Geography and Geology, University of Copenhagen, Øster Voldgade 10, DK-1350 Copenhagen K, Denmark; David B. Loope [dloope1@ unl.edu], Department of Geosciences, University of Nebraska, Lincoln, NE 68588-0340, Lincoln, Nebraska, USA.

This is an open-access article distributed under the terms of the Creative Commons Attribution License (for details please see creativecommons.org), which permits unrestricted use, distribution, and reproduction in any medium, provided the original author and source are credited. 
